\title{
Management of depression associated with HIV/AIDS and antiretroviral therapy
}

\author{
Mark Halman MD FRCPC
}

M Halman. Management of depression associated with HIV/AIDS and antiretroviral therapy. Can J Infect Dis Med Microbiol 2006;17(Suppl D):5D-9D.

Depressed mood is a common psychiatric complaint in persons with HIV/AIDS, with a meta-analysis indicating that the rates of depression within this group may be as high as double that of the general population. Depression may result from a biological diathesis to mood disorders, a physiological reaction to a medical illness or its treatment, and/or a psychological reaction to challenging life circumstances. Associated symptoms include sleep, energy and appetite disturbances; social withdrawal; diminished capacity to experience pleasure; diminished concentration; feelings of worthlessness, shame and guilt; and recurrent thoughts of death, including suicidal ideation. The emotionally and physically painful state of major depression is associated with decreased antiretroviral adherence and poorer HIV/AIDS disease outcomes.

Neuropsychiatric symptoms have been reported with several of the medications taken by patients with HIV/AIDS, including lamivudine, zidovudine, interferon and, most notably, efavirenz. However, data from several sources demonstrate that neuropsychiatric symptoms associated with efavirenz use are generally transient, with onset early after treatment initiation, peaking after one week and decreasing over the first one to four months of treatment. Recent comparative studies have not found elevated incident rates of major depression in patients treated with efavirenz, but they have confirmed the typical neuropsychiatric symptoms reported in earlier open-label studies and case reports. Becoming skilled in the management of depression and psychiatric symptoms is integral to the provision of comprehensive care for patients with HIV/AIDS.

\section{La prise en charge de la dépression associée au VIH-sida et aux antirétroviraux}

Les personnes atteintes de VIH-sida se plaignent souvent du problème psychiatrique qu'est le sentiment de dépression. D'après une méta-analyse, le taux de dépression au sein de ce groupe pourrait atteindre le double de celui de la population générale. La dépression peut être imputable à une diathèse biologique à des troubles de l'humeur, à une réaction physiologique à une maladie ou à son traitement ou à une réaction psychologique à une situation de vie difficile. Les symptômes connexes sont les troubles du sommeil, de l'énergie et de l'appétit, un retrait social, une diminution de la capacité de ressentir le plaisir, une baisse de la concentration, un sentiment d'inutilité, de honte et de culpabilité et des pensées récurrentes de mort, y compris l'idéation suicidaire. L'état émotif et physiquement douloureux de dépression majeure est relié à une diminution de l'observance du traitement et à de moins bonnes issues du VIH-sida.

Plusieurs des médicaments que prennent les personnes atteintes du VIHsida, y compris la lamivudine, la zidovudine, l'interféron et, surtout, l'efavirenz, sont reliés à des symptômes neuropsychiatriques. Cependant, selon les données provenant de plusieurs sources, les symptômes neuropsychiatriques associés à l'efavirenz sont généralement transitoires, se manifestant peu après le début du traitement, atteignant un sommet au bout d'une semaine et diminuant entre le premier et les quatre premiers mois du traitement. Des études comparatives récentes ne font pas état de taux accessoires élevés de dépression majeure chez les patients traités à l'efavirenz, mais elles ont confirmé les symptômes neuropsychiatriques classiques déclarés dans le cadre d'études ouvertes et de rapports de cas précédents. L'acquisition de compétences dans la prise en charge de la dépression et des symptômes psychiatriques fait partie intégrante de la prestation de soins complets aux patients atteints du VIH-sida.

Key Words: Antiretrovirals; Depression; Efavirenz; HIV/AIDS

$\mathrm{D}$ epressed mood is a common psychiatric complaint in persons with HIV/AIDS (1). Depression may result from a biological diathesis to mood disorders, a physiological reaction to a medical illness or its treatment, and/or a psychological reaction to challenging life circumstances. The diagnosis of a major depressive episode is made by identifying its classic symptoms as outlined in the Diagnostic and Statistical Manual of Mental Disorders, Fourth Edition (2). It is characterized by persistently depressed mood and associated symptoms of sleep, energy and appetite disturbances; social withdrawal; diminished capacity to experience pleasure; diminished concentration; feelings of worthlessness, shame and guilt; and recurrent thoughts of death, including suicidal ideation (2). Several studies (3-7) have found high rates of major depression in persons with HIV/AIDS, and a meta-analysis (8) confirmed that rates of major depression in persons with HIV/AIDS are at least double that of the general population. Major depression is an emotionally and physically painful state, associated with decreased antiretroviral adherence $(9,10)$ and poorer HIV/AIDS disease outcomes.

\section{ANTIRETROVIRAL TREATMENT-EMERGENT NEUROPSYCHIATRIC SYMPTOMS}

Neuropsychiatric symptoms, including depressed mood, agitation and insomnia, have been reported with several of the medications taken by patients with HIV/AIDS (11), including lamivudine $(12,13)$, zidovudine $(14,15)$, interferon (16) and, most notably, efavirenz $(17,18)$. In early controlled trials evaluating the safety and efficacy of efavirenz, a mean $53 \%$ of patients experienced central nervous system (CNS) symptoms and, less frequently, psychiatric symptoms (17-19). The most commonly reported symptoms included the feeling of being 'stoned', having vivid dreams and being anxious. Other reported symptoms included abnormal thinking, impaired concentration, amnesia, confusion, depersonalization, depression, agitation,

HIV Psychiatry Program and Centre for Research in Inner City Health, St Michael's Hospital, and Department of Psychiatry, University of

Toronto, Toronto, Ontario

Correspondence and reprints: Dr Mark Halman, St Michael's Hospital, Room 17033, Cardinal Carter Wing, 30 Bond Street, Toronto, Ontario

M5B 1W8. Telephone 416-864-3082, fax 416-864-3091, e-mail Halmanm@smh.toronto.on.ca 
TABLE 1

Summary of studies: Neuropsychiatric symptoms in patients on efavirenz-containing regimens versus patients on other regimens with depression as the outcome variable

\begin{tabular}{|c|c|c|c|c|}
\hline Author (reference), year & Study design & Treatment group & Number treated & Rate of depression \\
\hline \multirow[t]{2}{*}{ Fumaz et al (34), 2005} & \multirow{2}{*}{$\begin{array}{l}\text { Uncontrolled, } \\
\text { cross-sectional }\end{array}$} & Efavirenz & 22 & Prevalence reporting sadness $=37 \%$ \\
\hline & & Protease inhibitor & 9 & Prevalence reporting sadness $=15 \%$ \\
\hline \multirow[t]{2}{*}{ van Leth et al (35), 2004} & \multirow{2}{*}{$\begin{array}{l}\text { Randomized, } \\
\text { controlled }\end{array}$} & Efavirenz & 400 & Depression, grade 3 and $4=1.5 \%$ \\
\hline & & Nevirapine & 387 & Depression, grade 3 and $4=1.5 \%$ \\
\hline \multirow[t]{2}{*}{ von Giesen et al (36), 2003} & \multirow{2}{*}{$\begin{array}{l}\text { Uncontrolled, } \\
\text { retrospective }\end{array}$} & Efavirenz & 414 & Incidence of depression $=31 \%$ \\
\hline & & Nevirapine & 320 & Incidence of depression = $25 \%$ \\
\hline \multirow[t]{2}{*}{ Parienti et al (37), 2004} & \multirow{2}{*}{$\begin{array}{l}\text { Uncontrolled, } \\
\text { retrospective }\end{array}$} & Efavirenz & 40 & Prevalence of depression $=30 \%$ \\
\hline & & Nevirapine & 31 & Prevalence of depression $=23 \%$ \\
\hline \multirow[t]{2}{*}{ Clifford et al (38), 2005} & \multirow{2}{*}{$\begin{array}{l}\text { Randomized, } \\
\text { controlled }\end{array}$} & Efavirenz-containing regimen & 338 & \multirow{2}{*}{$\begin{array}{l}\text { No significant difference in } \\
\text { depression change scores }\end{array}$} \\
\hline & & Non-efavirenz-containing regimen & 169 & \\
\hline \multirow[t]{2}{*}{ Journot et al (39), 2006} & \multirow{2}{*}{$\begin{array}{l}\text { Randomized, } \\
\text { controlled }\end{array}$} & Efavirenz & 178 & Incidence of depression $=8 \%$ \\
\hline & & Protease inhibitor & 177 & Incidence of depression $=7 \%$ \\
\hline
\end{tabular}

euphoria, insomnia, somnolence and, rarely, hallucinations (18). Treatment-emergent neuropsychiatric side effects were usually reported soon after the first dose, with a median onset of one day, and then generally subsided over the first one to four months of treatment. Compared with a non-efavirenzcontaining regimen (zidovudine, lamivudine and indinavir) $(17,19)$, there were more neuropsychiatric side effects in the efavirenz-containing protocol group (53\% versus 26\%) (17). Antiretroviral regimen discontinuation due to CNS symptoms was higher, with $2.1 \%$ of patients discontinuing efavirenz therapy compared with $1.1 \%$ of patients in the non-efavirenzcontaining treatment arms (18).

With widespread use, data on psychiatric symptoms in efavirenz-treated patients continues to be reported from several sources, including case reports, observational cohorts and comparative trials. Severe depression with suicide attempt (20-22), mania (23), recurrence of post-traumatic stress disorder (24) and acute psychotic episodes $(25,26)$ with onset temporally related to initiation of efavirenz have all been described in case reports. Some of these reports suggest an association between the emergence of psychotic symptoms or severe depression and elevated plasma efavirenz levels (20,27-29).

Observational studies in community settings that reflect experience with efavirenz use in a broad range of patients, including those with mental health and substance abuse disorders, have also reported a characteristic neuropsychiatric syndrome associated with the use of efavirenz. In a study using retrospective recall of experiences, Lochet et al (30) reported high rates of neuropsychiatric symptoms before treatment, which increased in prevalence in the first month following treatment initiation and then steadily fell with continued treatment, with an overall $6 \%$ discontinuation rate due to neuropsychiatric side effects. Patients who recalled no symptoms before the initiation of therapy did report symptoms of sadness $(20 \%)$, anxiety $(15 \%)$ and suicidal ideation (9\%) that materialized in the first month of treatment, suggesting that psychiatric symptoms may emerge even in patients who are feeling mentally healthy at the time of regimen initiation. In an openlabel, prospective study, Blanch et al (31) stated that $71 \%$ of patients reported at least one neuropsychiatric side effect associated with efavirenz use, with a discontinuation rate of $13 \%$. Patients maintained on efavirenz treatment showed an overall reduction in levels of distress on longer term follow-up, reflecting the benefits that come with successful treatment. In a small, open-label study of 17 patients on longer term (median 18 months) efavirenz treatment, Gutierrez et al (32) reported persistent, generally mild-to-moderate neuropsychiatric symptoms in $10(58.8 \%)$ of those patients. Four patients, including two with significant depression, required efavirenz discontinuation. Their results also suggest that patients with higher plasma efavirenz levels may be at greater risk of experiencing neuropsychiatric symptoms.

Data from studies that compared neuropsychiatric symptoms in patients on efavirenz-containing regimens with patients on other regimens also suggest that transient neuropsychiatric symptoms occur more frequently in efavirenz-treated patients (33-39) (Table 1). One prospective study (33) compared neuropsychiatric side effects in patients who had failed a regimen containing a protease inhibitor (PI) who were then randomly assigned to start either a new PI or efavirenz. In that study, Fumaz et al (33) reported high rates of neuropsychiatric symptoms on initiation of the efavirenz regimen, with symptoms decreasing over time but exceeding rates reported by patients on PIs at all time points. In a subsequent cross-sectional study comparing patients who had been on either efavirenz-containing regimens or PI-containing regimens for at least one year, Fumaz et al (34) reported that patients on the efavirenz regimens continued to experience psychiatric symptoms of sadness, mood changes and irritability, also at rates that exceeded those on PI regimens. Both groups reported similarly good levels of quality of life and judged the persistent neuropsychiatric symptoms to be mild and generally tolerable; however, the study did suggest that subjective neuropsychiatric symptoms associated with efavirenz use may persist in some patients for a longer duration than had been previously reported (34). In the $2 \mathrm{NN}$ study comparing efavirenz and nevirapine, van Leth et al (35) found relatively low rates of composite CNS/psychiatric side effects in all treatment groups, although more severe grade 3 and 4 neuropsychiatric adverse events were reported only in patients taking efavirenz. In a large retrospective study of patients referred for neuropsychological assessment, von Giesen et al (36) found high rates of incident depression in patients treated with either efavirenz $(31 \%)$ or nevirapine $(25 \%)$. Cases of incident psychosis in this study were rare, and attention and memory issues 
were equal in both groups (9\%) (36). Parienti et al (37) also found comparable rates of depression reported in patients taking efavirenz- $(30 \%)$ and nevirapine- $(23 \%)$ based regimens in a small retrospective analysis.

A recent substudy by Clifford et al (38) of a randomized controlled trial that compared efavirenz-containing regimens and non-efavirenz-containing regimens reported on neuropsychological assessments collected prospectively on patients through 24 weeks of antiretroviral treatment. In the study, no statistically significant differences in neuropsychological performance were found at any time points between the groups. The study did confirm the presence of the typical subjective neuropsychiatric experiences described in earlier open studies, with the usual time course of onset occurring early after initiation of efavirenz, peaking at week 1 , and usually decreasing over the first month of treatment. The study found high levels of anxiety in patients initiated on both regimens and no statistically significant difference in changes in depression or anxiety scores between the groups. Significantly more patients required treatment regimen modification due to neuropsychiatric symptoms in the efavirenz group $(6 \%)$ than in the non-efavirenz-containing regimen group (0\%) (38). Another comparative study (39) looked at patients who were randomly assigned to either remain on their PI-based regimen or switch to an efavirenz-containing regimen. The study also demonstrated no increased incidence of depressive disorders associated with efavirenz use. The investigators did find high rates of depressive disorders in both treatment groups and concluded that there was an increased likelihood of incident cases of depression among patients with a history of depression, regardless of treatment arm (39). No studies have reported on the optimum management of neuropsychiatric symptoms associated with efavirenz treatment, and there is no evidence to suggest whether it is better to modify the efavirenz-containing regimen or to use standard psychiatric interventions to manage the emergent symptoms.

\section{TREATMENT AND MANAGEMENT OF MAJOR DEPRESSION IN HIV-POSITIVE PATIENTS}

Identification and management of depressive symptoms is an integral component of comprehensive HIV patient care. A number of studies $(40,41)$ have demonstrated the important relationship between depression and HIV disease progression, a relationship that persists even in the era of highly active antiretroviral therapy (HAART) (42). The effects of depression may influence HIV disease progression on several levels, including through biological mechanisms that link the two processes (43), delayed health care access and delayed initiation of HAART $(44,45)$, and impact on HAART medication adherence $(46,47)$.

Optimal primary care treatment of major depression includes psychopharmacological management combined with psychotherapy (48). Antidepressant medication, cognitive behavioural therapy and interpersonal therapy have all proven to be effective treatments for depression in the general population, although psychotherapy alone may be less effective than medication management in patients with severe depressive symptoms (49). Some trials (50-52) have demonstrated the effectiveness of psychotherapy for symptom reduction in depressed HIV-positive patients, and a recent cohort study (44) demonstrated that mental health therapy with or without the use of antidepressants was associated with increased probability of HAART use in depressed HIV-positive women. Several
TABLE 2

Antidepressant drugs that are recommended as therapeutic options in HIV-positive patients, together with the usual doses

\begin{tabular}{|c|c|c|c|}
\hline $\begin{array}{l}\text { Class/individual } \\
\text { agent }\end{array}$ & $\begin{array}{c}\text { Usual } \\
\text { starting } \\
\text { dose (mg) }\end{array}$ & $\begin{array}{l}\text { Usual } \\
\text { treatment } \\
\text { dose }(\mathrm{mg})\end{array}$ & $\begin{array}{l}\text { Maximum } \\
\text { recommended } \\
\text { dose }(\mathrm{mg})\end{array}$ \\
\hline \multicolumn{4}{|l|}{ SSRIs } \\
\hline Citalopram* & 10 & 20 & 60 \\
\hline Sertraline* & 50 & $50-200$ & 200 \\
\hline Paroxetine $^{\dagger}$ & 10 & 20 & 60 \\
\hline Fluoxetine*† & 10 & 20 & 80 \\
\hline Escitalopram & 10 & $10-20$ & 30 \\
\hline \multicolumn{4}{|l|}{ SNRIs } \\
\hline Venlafaxine XR & 37.5 & $150-225$ & 375 \\
\hline \multicolumn{4}{|l|}{ NaSSAs } \\
\hline Mirtazapine* & 30 & 30 & 60 \\
\hline \multicolumn{4}{|l|}{ TCAs } \\
\hline Nortriptyline & 10 & $50-150$ & 200 \\
\hline Imipramine ${ }^{\dagger}$ & 25 & $75-200$ & 300 \\
\hline Desipramine & 25 & $100-200$ & 300 \\
\hline Amitriptyline & 25 & $75-200$ & 300 \\
\hline \multicolumn{4}{|l|}{ NDRIs } \\
\hline Bupropion SR* & 100 & $150-300$ & $300-450$ \\
\hline
\end{tabular}

*Open-label trial; ${ }^{\dagger}$ Randomized controlled trial. NaSSA Noradrenergic and specific serotonergic antidepressant; NDRI Noradrenergic and dopamine reuptake inhibitor; SNRI Serotonin-norepinephrine reuptake inhibitor; SSRI Selective serotonin reuptake inhibitor; TCA Tricyclic antidepressant. Notes: 1. The more debilitated the patient or the more evidence of organic brain disease, the lower the starting dose should be. Also, dosing titration should be done more slowly. 2. All antidepressants carry side effects and risks, including agitation. In rare cases, patients starting on antidepressants have experienced an intensification or precipitation of suicidal ideation. All patients started on antidepressants need to be monitored for emergent agitation. 3. All antidepressants may precipitate manic episodes, particularly in patients with a personal or family history of bipolar disorder. Patients with a history of bipolar disorder should be started on mood stabilizer therapy rather than an antidepressant alone. 4. The metabolism of fluoxetine, sertraline, amitriptyline, imipramine, desipramine, nortriptyline and bupropion SR may all be affected by $P 450$ enzyme inhibition by some antiretroviral medications, such as ritonavir, and may require dose modification of the antidepressant. Fluoxetine may also inhibit the metabolism of some antiretroviral agents. For more information on drug interactions go to <www.tthhivclinic.com/pdf/psych-int.pdf>

antidepressant medications, found to be effective in the treatment of major depression in the general population, have also proven effective in decreasing depressive symptoms in HIVpositive patients (Table 2). Open-label trials in depressed HIVpositive patients have shown the treatment benefits of several selective serotonin reuptake inhibitors (SSRIs), including citalopram (53), sertraline (54), fluoxetine (55) and mirtazapine (56), as well as the agent bupropion (57). Randomized, placebo-controlled trials have demonstrated reductions in depressive symptoms using the SSRIs paroxetine (58) and fluoxetine (59) and the tricyclic antidepressant imipramine $(58,60)$. A recent meta-analysis $(61)$ of those trials confirmed that treatment with antidepressant medication is efficacious in HIV-positive patients, but cautions that the results may not be generalizable due to underrepresentation of women and minorities in the treatment studies.

Major depression in patients with HIV/AIDS is managed using standard psychiatric interventions, and these are useful regardless of the presumed underlying cause of the major depression. To date, there are no studies that provide evidence for the 
optimal management of depression in the context of efavirenz treatment. Clinical options include the use of standard psychiatric interventions and/or discontinuation of efavirenz, and must take into account patient preference and antiretroviral options.

\section{Dosage}

For all HIV-positive patients with major depression, antidepressant treatment is generally initiated with the SSRI agents because they are the best tolerated and least likely to result in problematic drug interactions with antiretroviral agents (62). Antidepressant dosing in HIV-positive patients is essentially the same as in the depressed HIV-negative population; however, some caution must be used, particularly in patients with advanced systemic HIV disease and those on multiple medications. While drug interactions between antiretroviral medications and antidepressants must be considered, they are not a reason to withhold antidepressant treatment. Clinically significant interactions have been reported when antiretroviral agents that are powerful inhibitors of the cytochrome P450 system, such as ritonavir, are combined with antidepressants that rely on this enzyme system for drug metabolism (63). Dosage adjustment may be necessary when adding PIs, particularly ritonavir, to a tricyclic antidepressant, bupropion or fluoxetine (64).

Antidepressant medications should be initiated at one-half of the recommended starting dose and titrated to the starting dose after seven days if the drug is well tolerated. Target treatment doses are the same as in the general population. The patient's clinical response and drug tolerability should be evaluated regularly, with special attention paid to patient safety, specifically assessment of suicide risk. Treatment response is anticipated at weeks 4 to 6 of optimal drug dosage. Antidepressant treatment dose should be optimized as tolerated. In cases of nonresponse to antidepressant therapy, it is essential to ensure correct diagnosis, including examining for systemic disorders (eg, hypothyroidism) or concurrent substance-related disorders that may be limiting treatment response. It is also important to ensure adequate adherence to antidepressant therapy, assess psychosocial supports, and direct patients to appropriate psychotherapy and counselling support services, as available. Continued nonresponse may be managed by switching antidepressants within a class (eg, from paroxetine to citalopram) or between classes (eg, from citalopram to venlafaxine, bupropion or nortriptyline) $(49,65,66)$, or with standard augmentation strategies (eg, adding lithium, triiodothyronine, buspirone or a second antidepressant, such as bupropion) (49,67). In depressed HIV-positive patients taking efavirenz, continued nonresponse to standard psychiatric interventions may necessitate drug discontinuation and substitution with another antiretroviral combination, or therapeutic drug monitoring of efavirenz levels, if available. Antidepressant medications should be maintained at full treatment doses for a minimum of six to nine months or longer if the patient has experienced frequent or recurrent depressive episodes, or episodes that are severe and/or difficult to treat $(68,69)$. Psychiatric consultation should be initiated for patients with nonresponse to standard antidepressant therapy, patients with significant suicidal ideation, patients with a history of bipolar mood disorder and patients with psychotic symptoms. Patients with concurrent substance-related disorders should be referred for integrated psychiatric and substance abuse treatment.

\section{CONCLUSIONS}

In summary, data from several sources confirm the presence of subjective neuropsychiatric symptoms associated with efavirenz use, with onset early after treatment initiation, peaking after one week and decreasing over the first one to four months of treatment. Some studies suggest the symptoms may persist in some patients for a longer duration and some, but not all, studies suggest that symptoms may be associated with elevated plasma efavirenz levels. No studies have systematically evaluated the management of these symptoms, but in some patients antiretroviral regimen modification is necessary. Several studies report high rates of psychiatric symptoms, including depression, in HIV-positive patients in general. As such, becoming skilled in the management of depression is integral to the provision of comprehensive care for patients with HIV/AIDS.

\section{REFERENCES}

1. Ferrando SJ, Goldman JD, Charness WE. Selective serotonin reuptake inhibitor treatment of depression in symptomatic HIV infection and AIDS. Improvements in affective and somatic symptoms. Gen Hosp Psychiatry 1997;19:89-97.

2. American Psychiatric Association. Diagnostic and Statistical Manual of Mental Disorders, 4th edn, text revision. Washington: American Psychiatric Association, 2000.

3. Atkinson H, Grant I, Kennedy CJ, et al. Prevalence of psychiatric disorders among men infected with human immunodeficiency virus. Arch Gen Psychiatry 1988;45:859-64.

4. Perkins DO, Stern RA, Golden RN, Murphy C, Naftolowitz D, Evans DL. Mood disorders in HIV infection: Prevalence and risk factors in a nonepicenter of the AIDS epidemic. Am J Psychiatry 1994;151:233-6.

5. Maj M, Janssen R, Starace F, et al. WHO Neuropsychiatric AIDS study, cross-sectional phase I. Study design and psychiatric findings. Arch Gen Psychiatry 1994;51:39-49

6. Dew MA, Becker JT, Sanchez J, et al. Prevalence and predictors of depressive, anxiety and substance use disorders in HIV-infected and uninfected men: A longitudinal evaluation. Psychol Med 1997;27:395-409.

7. Kelly B, Raphael B, Judd F, et al. Psychiatric disorder in HIV infection. Aust N Z J Psychiatry 1998;32:441-53.

8. Ciesla JA, Roberts JE. Meta-analysis of the relationship between HIV infection and risk for depressive disorders. Am J Psychiatry 2001;158:725-30

9. Chesney MA. Factors affecting adherence to antiretroviral therapy. Clin Infect Dis 2000;30(Suppl 2):S171-6.

10. Paterson DL, Swindells S, Mohr J, et al. Adherence to protease inhibitor therapy and outcomes in patients with HIV infection. Ann Intern Med 2000;133:21-30. (Erratum in 2002;136:253).

11. Worth JL, Halman MH. HIV disease/AIDS. In: Rundell JR, Wise MG, eds. American Psychiatric Press Textbook of Consultation-Liaison Psychiatry. Washington: American Psychiatric Press, 1996:832-77.

12. Enzensberger W, von Giesen HJ; German Neuro-AIDS study group (DNAA). Antiretroviral therapy (ART) from a neurological point of view. Eur J Med Res 1999;4:456-62.

13. 3TC Product Monograph. Mississauga: Glaxo Wellcome Inc, 1999

14. Rachlis A, Fanning MM. Zidovudine toxicity. Clinical features and management. Drug Saf 1993;8:312-20.

15. Retrovir Product Monograph. Mississauga: Glaxo Wellcome Inc, 2000.

16. Valentine AD, Meyers CA, Kling MA, Richelson E, Hauser P. Mood and cognitive side effects of interferon-alpha therapy. Semin Oncol 1998;25(Suppl 1):39-47.

17. Staszewski S, Morales-Ramirez J, Tashima KT, et al. Efavirenz plus zidovudine and lamivudine, efavirenz plus indinavir, and indinavir plus zidovudine and lamivudine in the treatment of HIV-1 infection in adults. Study 006 Team. N Engl J Med 1999;341:1865-73.

18. Sustiva Product Monograph. Mississauga: DuPont Pharma Inc, 2001.

19. Haas DW, Fessel WJ, Delapenha RA, et al. Therapy with efavirenz plus indinavir in patients with extensive prior nucleoside reversetranscriptase inhibitor experience: A randomized, double-blind, placebocontrolled trial. J Infect Dis 2001;183:392-400.

20. Hasse B, Günthard HF, Bleiber G, Krause M. Efavirenz intoxication due to slow hepatic metabolism. Clin Infect Dis 2005;40:e22-3.

21. Puzantian T. Central nervous system adverse effects with efavirenz: Case report and review. Pharmacotherapy 2002;22:930-3. 
22. Allin M, Reeves I, Tennant-Flowers M, Everal I. Frequency of serious psychiatric adverse events with efavirenz. Antiviral Ther 2003;8:L85-6. [Abst 129]

23. Shah MD, Balderson K. A manic episode associated with efavirenz therapy for HIV infection. AIDS 2003;17:1713-4.

24. Moreno A, Labelle C, Samet JH. Recurrence of post-traumatic stress disorder symptoms after initiation of antiretrovirals including efavirenz: A report of two cases. HIV Med 2003;4:302-4

25. de la Garza CL, Paoletti-Duarte S, Garcia-Martin C, Gutierrez-Casares JR. Efavirenz-induced psychosis. AIDS 2001;15:1911-2.

26. van Twillert G, van Santen G, Godfried MH. [Severe psychosis in an African woman due to the antiretroviral agent efavirenz.] Ned Tijdschr Geneeskd 2005;149:2687-9.

27. Bickel M, Stephan C, Rottmann C, et al. Severe CNS side-effect and persistent high efavirenz plasma levels in a patient with HIV/HCV coinfection and liver cirrhosis. Scand J Infect Dis 2005;37:520-2.

28. Sabato S, Wesselingh S, Fuller A, Ray J, Mijch A. Efavirenz-induced catatonia. AIDS 2002;16:1841-2

29. Brennan-Benson P, Lyus R, Harrison T, Pakianathan M, Macallan D. Pharmacokinetic interactions between efavirenz and rifampicin in the treatment of HIV and tuberculosis: One size does not fit all. AIDS 2005;19:1541-3.

30. Lochet P, Peyriere H, Lotthe A, Mauboussin JM, Delmas B, Reynes J. Long-term assessment of neuropsychiatric adverse reactions associated with efavirenz. HIV Med 2003;4:62-6.

31. Blanch J, Martinez E, Rousaud A, et al. Preliminary data of a prospective study on neuropsychiatric side effects after initiation of efavirenz. J Acquir Immune Defic Syndr 2001;27:336-43.

32. Gutierrez F, Navarro A, Padilla S, et al. Prediction of neuropsychiatric adverse events associated with long-term efavirenz therapy, using plasma drug level monitoring. Clin Infect Dis 2005;41:1648-53.

33. Fumaz CR, Tuldra A, Ferrer MJ, et al. Quality of life, emotional status, and adherence of HIV-1-infected patients treated with efavirenz versus protease inhibitor-containing regimens. J Acquir Immune Defic Syndr 2002;29:244-53.

34. Fumaz CR, Munoz-Moreno JA, Molto J, et al. Long-term neuropsychiatric disorders on efavirenz-based approaches: Quality of life, psychologic issues, and adherence. J Acquir Immune Defic Syndr 2005;38:560-5.

35. van Leth F, Phanuphak P, Ruxrungtham K, et al; 2NN Study team. Comparison of first-line antiretroviral therapy with regimen including nevirapine, efavirenz, or both drugs, plus stavudine and lamivudine: A randomised open-label trial, the 2NN Study. Lancet 2004;363:1253-63

36. von Giesen HJ, Koller H, de Nocker D, Haslinger BA, Arendt G. Long-term safety and efficacy of NNRTI within the central nervous system. HIV Clin Trials 2003;4:382-90.

37. Parienti JJ, Massari V, Descamps D, et al. Predictors of virologic failure and resistance in HIV-infected patients treated with nevirapine- or efavirenz-based antiretroviral therapy. Clin Infect Dis 2004;38:1311-6.

38. Clifford DB, Evans S, Yang Y, et al. Impact of efavirenz on neuropsychological performance and symptoms in HIV-infected individuals. Ann Intern Med 2005;143:714-21.

39. Journot V, Chene G, De Castro N, et al; ALIZE Study Group. Use of efavirenz is not associated with a higher risk of depressive disorders: A substudy of the randomized clinical trial ALIZE-ANRS 099. Clin Infect Dis 2006;42:1790-9. (Erratum in 2006;43:270).

40. Ickovics JR, Hamburger ME, Vlahov D, et al; HIV Epidemiology Research Study Group. Mortality, CD4 cell count decline, and depressive symptoms among HIV-seropositive women: Longitudinal analysis from the HIV Epidemiology Research Study. JAMA 2001;285:1466-74.

41. Mayne TJ, Vittinghoff E, Chesney MA, Barrett DC, Coates TJ. Depressive affect and survival among gay and bisexual men infected with HIV. Arch Intern Med 1996;156:2233-8.

42. Ironson G, O'Cleirigh C, Fletcher MA, et al. Psychosocial factors predict CD4 and viral load change in men and women with human immunodeficiency virus in the era of highly active antiretroviral treatment. Psychosom Med 2005;67:1013-21.

43. Cruess DG, Douglas SD, Petitto JM, et al. Association of resolution of major depression with increased natural killer cell activity among HIV-seropositive women. Am J Psychiatry 2005;162:2125-30.

44. Cook JA, Grey D, Burke-Miller J, et al. Effects of treated and untreated depressive symptoms on highly active antiretroviral therapy use in a US multi-site cohort of HIV-positive women. AIDS Care 2006;18:93-100
45. Fairfield KM, Libman H, Davis RB, Eisenberg DM. Delays in protease inhibitor use in clinical practice. J Gen Intern Med 1999;14:395-401.

46. Ickovics JR, Meade CS. Adherence to antiretroviral therapy among patients with HIV: A critical link between behavioral and biomedical sciences. J Acquir Immune Defic Syndr 2002;31(Suppl 3):S98-102.

47. Gordillo V, del Amo J, Soriano V, Gonzalez-Lahoz J. Sociodemographic and psychological variables influencing adherence to antiretroviral therapy. AIDS 1999;13:1763-9.

48. Katon W, Von Korff M, Lin E, et al. Stepped collaborative care for primary care patients with persistent symptoms of depression: A randomized trial. Arch Gen Psychiatry 1999;56:1109-15.

49. Kennedy SH, Lam RW, Cohen NL, Ravindran AV; CANMAT Depression Work Group. Clinical guidelines for the treatment of depressive disorders. IV. Medications and other biological treatments. Can J Psychiatry 2001;46(Suppl 1):38S-58S.

50. Markowitz JC, Klerman GL, Clougherty KF, et al. Individual psychotherapies for depressed HIV-positive patients. Am J Psychiatry 1995; 152:1504-9.

51. Lee MR, Cohen L, Hadley SW, Goodwin FK. Cognitive-behavioral group therapy with medication for depressed gay men with AIDS or symptomatic HIV infection. Psychiatr Serv 1999;50:948-52.

52. Targ EF, Karasic DH, Diefenbach PN, Anderson DA, Bystritsky A, Fawzy FI. Structured group therapy and fluoxetine to treat depression in HIV-positive persons. Psychosomatics 1994;35:132-7.

53. Currier MB, Molina G, Kato M. Citalopram treatment of major depressive disorder in Hispanic HIV and AIDS patients: A prospective study. Psychosomatics 2004;45:210-6.

54. Rabkin JG, Wagner G, Rabkin R. Effects of sertraline on mood and immune status in patients with major depression and HIV illness: An open trial. J Clin Psychiatry 1994;55:433-9.

55. Rabkin JG, Rabkin R, Wagner G. Effects of fluoxetine on mood and immune status in depressed patients with HIV illness. J Clin Psychiatry 1994:55:92-7.

56. Elliott AJ, Roy-Byrne PP. Mirtazapine for depression in patients with human immunodeficiency virus. J Clin Psychopharmacol 2000;20:265-7.

57. Currier MB, Molina G, Kato M. A prospective trial of sustainedrelease bupropion for depression in HIV-seropositive and AIDS patients. Psychosomatics 2003;44:120-5.

58. Elliott AJ, Uldall KK, Bergam K, Russo J, Claypoole K, Roy-Byrne PP. Randomized, placebo-controlled trial of paroxetine versus imipramine in depressed HIV-positive outpatients. Am J Psychiatry 1998;155:367-72.

59. Zisook S, Peterkin J, Goggin KJ, Sledge P, Atkinson JH, Grant I. Treatment of major depression in HIV-seropositive men. HIV Neurobehavioral Research Center Group. J Clin Psychiatry 1998;59:217-24.

60. Rabkin JG, Rabkin R, Harrison W, Wagner G. Effect of imipramine on mood and enumerative measures of immune status in depressed patients with HIV illness. Am J Psychiatry 1994;151:516-23.

61. Himelhoch S, Medoff DR. Efficacy of antidepressant medication among HIV-positive individuals with depression: A systematic review and meta-analysis. AIDS Patient Care STDS 2005;19:813-22.

62. Bialer PA, Bluestine SL, Termine AW, et al. Psychiatric implications for AIDS patients taking protease inhibitors. Psychosomatics 1998;39:183-4.

63. Tseng AL, Foisy MM. Significant interactions with new antiretrovirals and psychotropic drugs. Ann Pharmacother 1999;33:461-73.

64. DeSilva KE, Le Flore DB, Marston BJ, Rimland D. Serotonin syndrome in HIV-infected individuals receiving antiretroviral therapy and fluoxetine. AIDS 2001;15:1281-5.

65. Rush AJ, Trivedi MH, Wisniewski SR, et al; STAR*D Study Team. Bupropion-SR, sertraline, or venlafaxine-XR after failure of SSRIs for depression. N Engl J Med 2006;354:1231-42.

66. Fava M, Rush AJ, Wisniewski SR, et al. A comparison of mirtazapine and nortriptyline following two consecutive failed medication treatments for depressed outpatients: A STAR*D report. Am J Psychiatry 2006;163:1161-72.

67. Trivedi MH, Fava M, Wisniewski SR, et al; STAR*D Study Team. Medication augmentation after the failure of SSRIs for depression. N Engl J Med 2006;354:1243-52.

68. Lam RW, Kennedy SH. Evidence-based strategies for achieving and sustaining full remission in depression: Focus on metaanalyses. Can J Psychiatry 2004:49(3 Suppl 1):17S-26S.

69. Halman MH, Bialer P, Worth JL, Rourke SB. HIV Disease/AIDS. In: Rundell JR, Wise MG, eds. American Psychiatric Press Textbook of Consultation-Liaison Psychiatry, 2nd edn. Washington: American Psychiatric Press, 2002:807-51. 


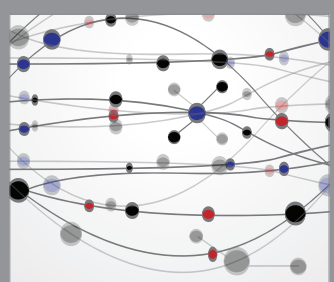

The Scientific World Journal
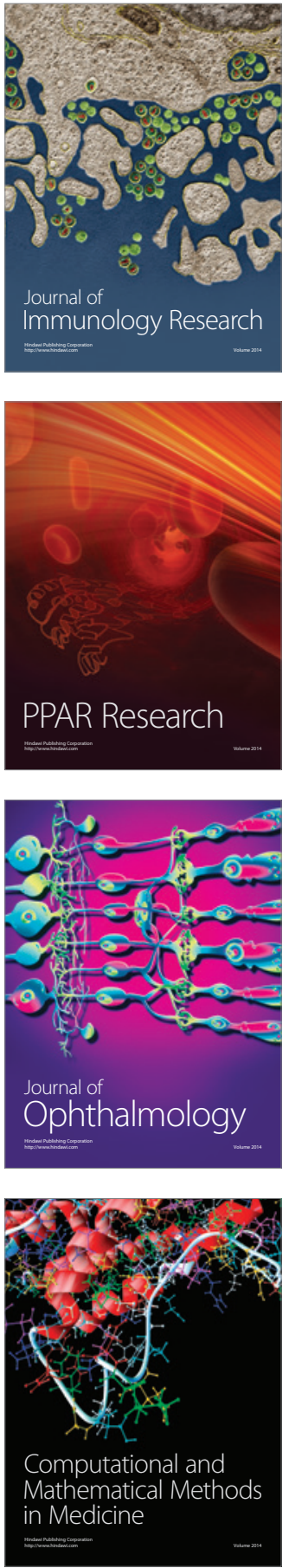

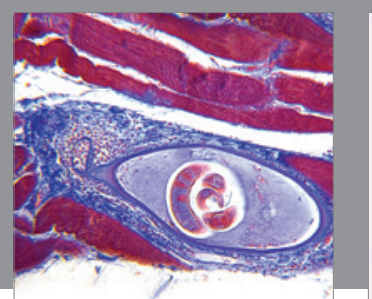

Gastroenterology Research and Practice

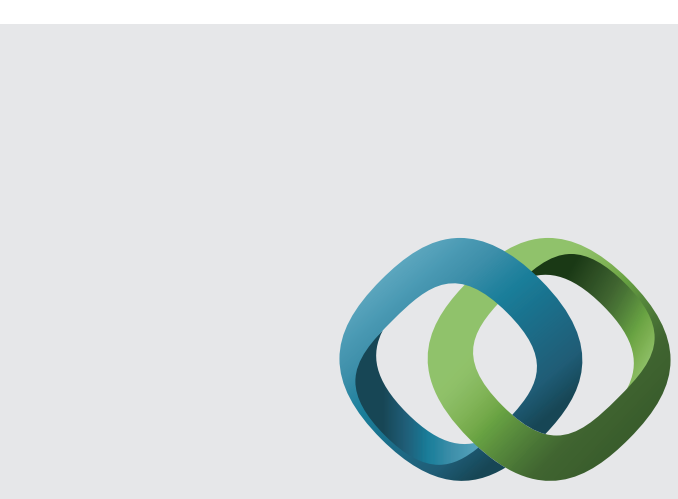

\section{Hindawi}

Submit your manuscripts at

http://www.hindawi.com
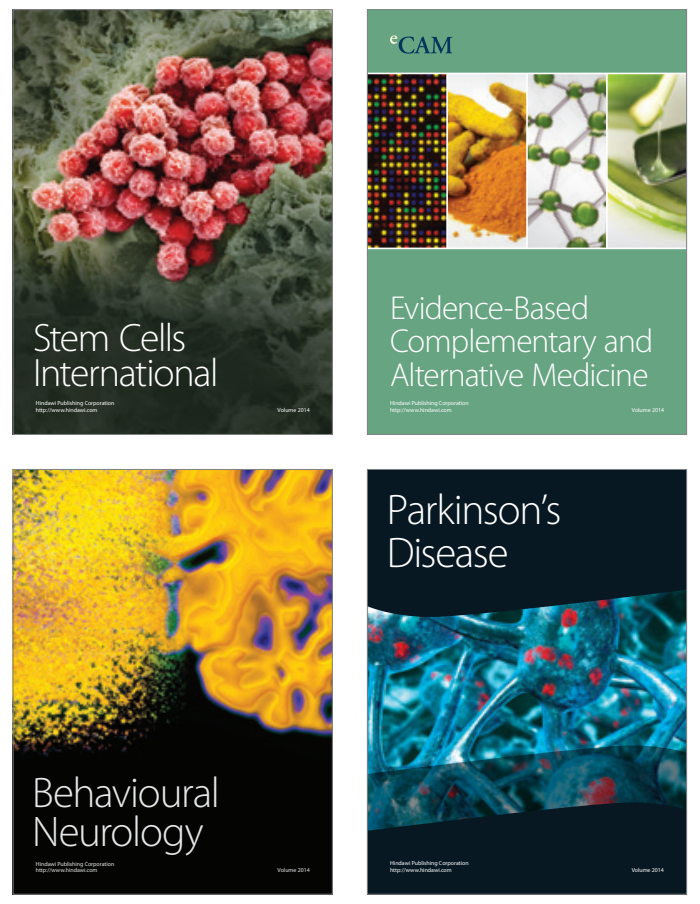
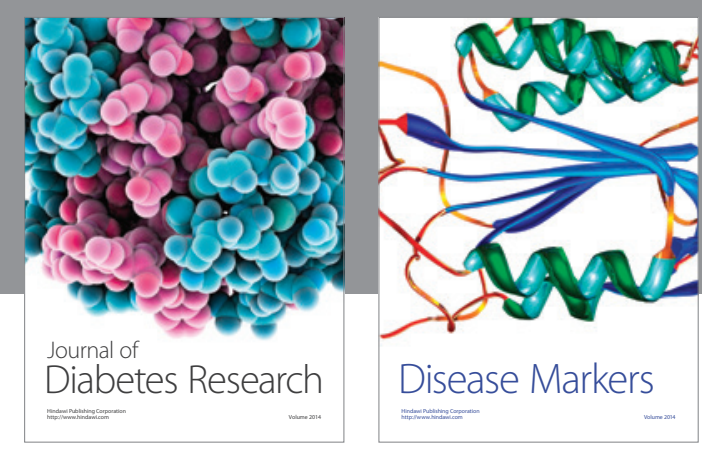

Disease Markers
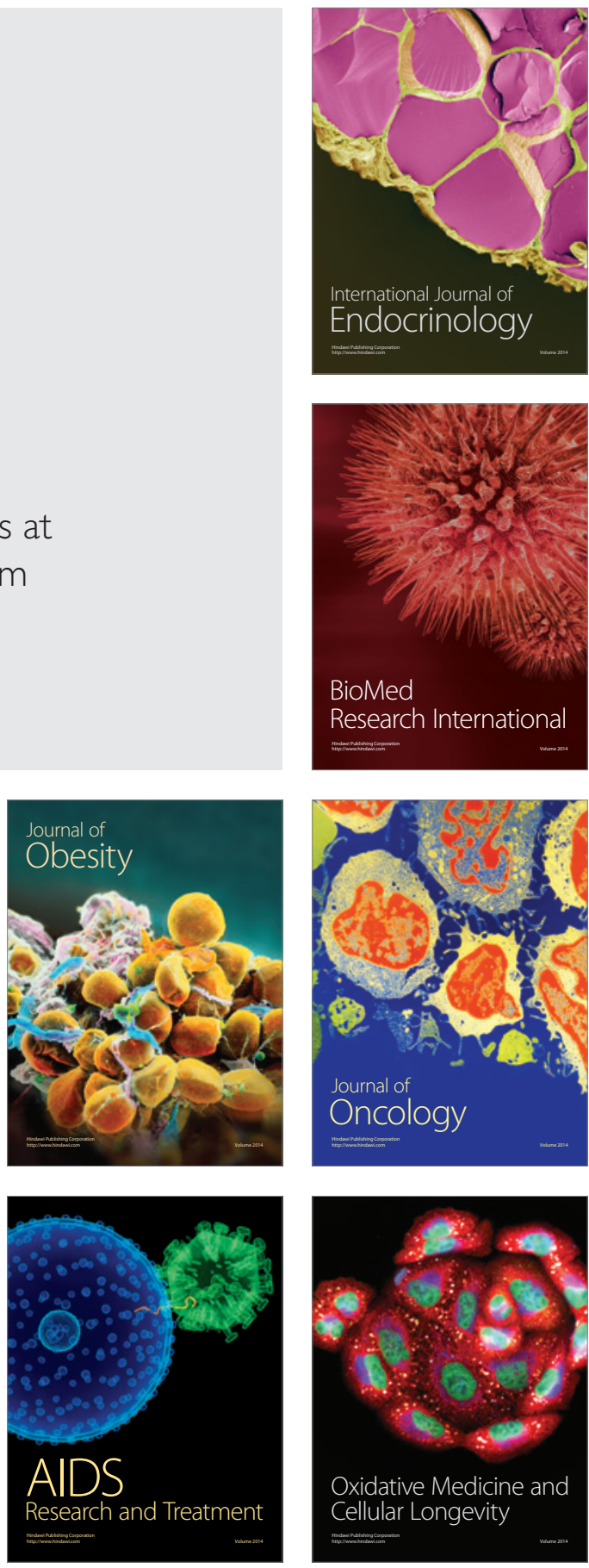